\title{
Low dietary zinc intake attenuates the efficacy of 2,4-thiazolidinedione on reducing hyperglycemia in $\mathrm{db} / \mathrm{db}$ mice (Short communication)
}

\author{
Y-M Song ${ }^{1}$, H-Y Hsu ${ }^{2}$, M-D Chen ${ }^{1,3}$ \\ ${ }^{1}$ Division of Endocrinology and Metabolism, Department of Internal Medicine, \\ Taichung Veterans General Hospital, Taichung, Taiwan \\ ${ }^{2}$ Department of Industrial Management, Overseas Chinese University, Taichung, Taiwan \\ ${ }^{3}$ General Education Center, Overseas Chinese University, Taichung, Taiwan
}

Received: July 16, 2014

Accepted: July 31, 2015

Zinc (Zn) has the potential of regulating the action of thiazolidinedione (TZD), an anti-diabetic drug. Since some diabetic patients cannot achieve optimal glycemic control when receiving TZD, we investigated if $\mathrm{Zn}$ deficiency affects TZD's efficacy in glucose metabolism. Diabetic mice were fed diets containing 3 or $30 \mathrm{mg} / \mathrm{kg}$ Zn for 6 weeks. Thereafter, all mice were oral gavaged with 2,4-thiazolidinedione. Our results showed that blood glucose values at fasting and during the glucose tolerance test were significantly higher in low-Zn mice than those of adequate- $\mathrm{Zn}$ mice. Thus, low Zn intake may attenuate TZD's efficacy on reducing diabetic hyperglycemia.

Keywords: db/db mice, hyperglycemia, NIDDM, thiazolidinedione, zinc deficiency

Type 2 diabetes mellitus has become a serious public health problem worldwide (13). The pivotal mediator for the various manifestations of diabetic complications, including cardiovascular disorders, may be attributed to the oxidative stress derived from factors like hyperglycemia and inflammatory response (2). Zinc (Zn) closely participates in the metabolism of carbohydrate, protein and fat (7). Its deficiency causes a variety of physiological defects, such as growth retardation, immune depression, and acrodermatitis, etc (10). However, reduced $\mathrm{Zn}$ intake has become prevalent in many countries (18). $\mathrm{Zn}$ also plays an important role in mediating the production and signaling of insulin (17). Diabetic subjects usually have hypozincemia and hyperzincuria, and correction of the $\mathrm{Zn}$ status has been proposed as a therapeutic option for diabetic patients (6).

Peroxisome proliferators-activated receptor (PPAR) can act as transcription factor to regulate the activity of various genes, such as nuclear factor kappa B (NF- $\mathrm{B})(12)$. Although the full pharmacological mechanisms remain unclear, PPAR agonists, of note the thiazolidinediones (TZDs) have been widely administered as an insulin sensitizer to type 2 diabetic patients (12). However, these TZDs have been withdrawn or under restriction due to

Corresponding author: Prof. Dr. Ming-Der Chen

General Education Center, Overseas Chinese University

No. 100 Chiao-Kwang Road, Taichung 40721, Taiwan

Phone: +886-4-27016855 ext. 2182; E-mails: mdchen@ocu.edu.tw; mdchen1104@gmail.com 
the increased risk of hepatitis (troglitazone), bladder cancer (pioglitazone), and cardiovascular events (rosiglitazone), respectively. Upon re-evaluation of new data in 2013, the US-FDA lifted the restriction on prescribing rosiglitazone.

$\mathrm{Zn}$ is known as an essential constituent of PPARs (4). Furthermore, $\mathrm{Zn}$ deficiency reduces anti-inflammatory activity of $T Z D$, and the decrease is reversed after $\mathrm{Zn}$ repletion $(8,11)$. In clinical practice, some diabetic patients cannot achieve optimal glycemic control when given TZD therapy (5). The failure of TZD therapy may be associated with the intrinsic difference in adiposity among patients, which is complicated by TZD's effect on adipocyte differentiation and altered production of adipokines (16). It also seems reasonable to suppose that some patients with TZD inefficacy may have $\mathrm{Zn}$ deficiency. The purpose of this preliminary study was to examine if low dietary $\mathrm{Zn}$ intake attenuates the efficacy of 2,4-thiazolidinedione on reducing diabetic hyperglycemia.

\section{Materials and Methods}

Weanling male $\mathrm{db} / \mathrm{db}$ mice were obtained from the Jackson Laboratory (Bar Harbor, ME, USA). The $\mathrm{db} / \mathrm{db}$ mouse, characterized by hyperglycemia, hyperinsulinemia, and leptinresistant obesity, closely resembles the metabolic profile of type 2 diabetes mellitus. Mice at 5 weeks of age were assigned to diet with low $(3 \mathrm{mg} / \mathrm{kg})$ or adequate $(30 \mathrm{mg} / \mathrm{kg}) \mathrm{Zn}$. Each group contained 7 mice. Diets were prepared as in a previous study (15). Throughout the study, all mice had free access to diet and deionized water.

At the end of a 6-week $\mathrm{Zn}$ treatment period, fasting blood samples were obtained by tail cutting from all mice. Circulating concentrations of glucose, insulin, and $\mathrm{Zn}$ were measured. Thereafter, without changing their original $\mathrm{Zn}$ treatment, all mice were given 2,4-thiazolidinedione (30 mg/kg BW/d, Sigma, St. Louis, MO, USA) for a further week by oral gavage. After completion of 2,4-thiazolidinedione administration, mice were fasted for $6 \mathrm{~h}$ and subjected to the oral glucose tolerance test ( $1 \mathrm{~g}$ glucose $/ \mathrm{kg} \mathrm{BW})$ by following the method described previously (1). A protocol for animal care procedure was approved by the OCU Research Management and Review Committee (Ocit-RD-99A-061).

Body fat content was determined by a body composition analyzer (EM-SCAN Inc., Springfield, IL, USA). Glucose level was measured with a blood glucose meter (Lifescan Surestep, Johnson \& Johnson, Milpitas, CA, USA). Insulin measurement (Crystal Chem Inc., Chicago, IL, USA) was performed by enzyme-linked immunoabsorbent assay. Zn concentration was determined by an atomic absorption spectrophotometer (Instrumenation Lab., Wilmington, MA, USA).

All measurements were done on all 7 mice in each group, and the data were presented as the mean \pm SD. Statistical analyses of the results were conducted by ANOVA and unpaired Student's $t$-test with a commercial package, KaleidaGraph 3.6 for Macintosh. The difference was considered to be significant when $P$ value was $<0.05$.

\section{Results}

Our data showed that the mice fed low-Zn diet (LZ) had significantly decreased body weight and body fat but similar diet consumption when compared with mice with adequate $\mathrm{Zn}$ intake (AZ). LZ mice also had significantly higher glucose (36\%) and lower insulin (47\%) compared to that of AZ mice (Table I). 
Table I. Effects of dietary zinc treatment for 6 weeks on food intake, body weight, body fat, and determined plasma variables in $\mathrm{db} / \mathrm{db}$ mice

\begin{tabular}{|l|c|c|c|}
\hline & AZ group $(n=7)$ & LZ group $(n=7)$ & $P$ value \\
\hline Food intake $(\mathrm{g})$ & $5.8 \pm 1.0$ & $4.9 \pm 1.3$ & 0.173 \\
\hline Body weight $(\mathrm{g})$ & $33.5 \pm 2.4$ & $28.3 \pm 3.6$ & 0.010 \\
\hline Body fat $(\%)$ & $34.2 \pm 4.7$ & $25.6 \pm 3.5$ & 0.003 \\
\hline Glucose $(\mathrm{mM})$ & $18.2 \pm 3.0$ & $24.7 \pm 5.2$ & 0.019 \\
\hline Insulin $(\mathrm{pM})$ & $6294 \pm 1006$ & $3316 \pm 785$ & 0.001 \\
\hline Zinc $(\mu \mathrm{M})$ & $13.3 \pm 2.7$ & $12.0 \pm 5.1$ & 0.546 \\
\hline
\end{tabular}

Mean \pm SD. AZ group: adequate zinc diet (30 mg/kg); LZ group: low zinc diet (3 mg/kg)

After completion of 2,4-thiazolidinedione administration, fasting blood glucose values of both groups were decreased, though to a less extent in LZ mice, than those at preadministration period (AZ mice: from $18.2 \pm 3.0$ to $12.9 \pm 2.2 \mathrm{mM}, P=0.004$; $\mathrm{LZ}$ mice: from $24.7 \pm 5.2$ to $20.0 \pm 4.6 \mathrm{mM}, P=0.100$ ). LZ mice also exhibited impaired glucose tolerance, as manifested by higher blood glucose levels at 30 and $60 \mathrm{~min}$ after the glucose load (Fig. 1), resulting in a $39 \%$ increase in the AUC (area under curve in glucose challenge test) for glucose $(1532 \pm 408$ vs $1100 \pm 147 \mathrm{mM}, P=0.030)$.

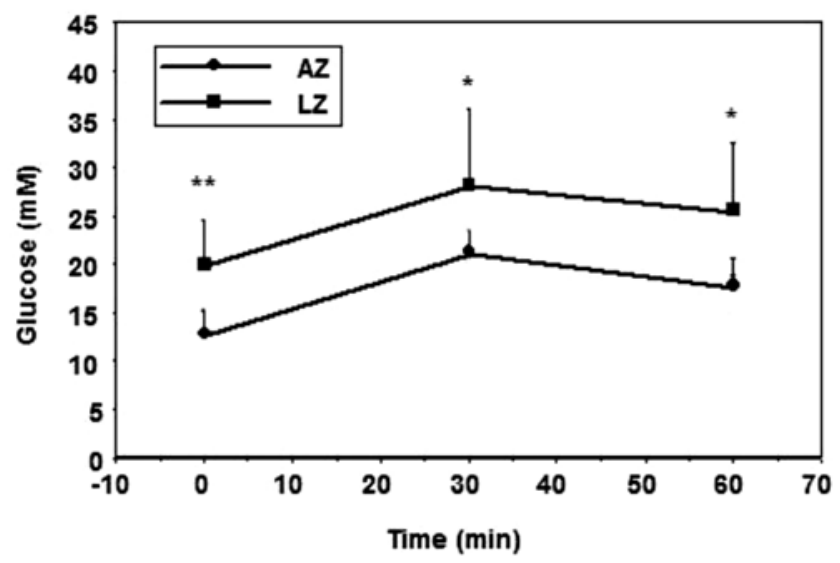

Fig. 1. Effects of 2, 4-thiazolidinedione treatment $(30 \mathrm{mg} / \mathrm{kg} / \mathrm{d})$ for a week on blood glucose levels after the administration of the glucose load (1 g glucose $/ \mathrm{kg}$, ip) in $\mathrm{db} / \mathrm{db}$ mice fed diets with $30 \mathrm{mg} / \mathrm{kg} \mathrm{Zn} \mathrm{(AZ)} \mathrm{or} 3 \mathrm{mg} / \mathrm{kg}$ $\mathrm{Zn}(\mathrm{LZ})$. Data are expressed as mean $\pm \mathrm{SD}$. There is significant difference $(*: P<0.05, * *: P<0.01)$ between groups at the same sampling time

\section{Discussion}

Consistent with previous studies $(6,15)$, low $\mathrm{Zn}$ intake markedly increased glucose and decreased insulin in $\mathrm{db} / \mathrm{db}$ mice. Since $\mathrm{Zn}$ mediates the production of insulin (17), higher glucose and lower insulin observed in $\mathrm{db} / \mathrm{db}$ mice fed low $\mathrm{Zn}$ diet might be attributed to $\mathrm{Zn}$ deficiency-induced reduction in insulin availability. Moreover, $\mathrm{Zn}$ deficiency worsened 
peripheral glucose utilization and lipogenesis which result in the reduction in body weight and body fat accumulation (15). However, whether Zn-deficiency-induced exacerbation of diabetic hyperglycemia is primarily due to the change in insulin synthesis, or its peripheral clearance, or other causes such as tissue $\mathrm{Zn}$ maldistribution (9), remains to be elucidated.

Extreme Zn deficiency causes anorexia (18). However, according to our experience and previous studies $(6,14,15)$, low $\mathrm{Zn}$, but not totally depleted, has no significant influence on the amount of food intake. A pair-fed group of mice was thus not included in this study. During a 7-week period of low Zn treatment, our mice exhibited no obvious disorders, such as skin lesions or growth retardation (assessed by tail length, data not shown). Consistent with previous studies $(14,15)$ using various $\mathrm{Zn}$ doses $(0.4$ or $5 \mathrm{mg} / \mathrm{kg})$, serum $\mathrm{Zn}$ levels did not markedly alter by low $\mathrm{Zn}$ intake. Our data indicated that a short-term period ( 7 weeks) of low dietary Zn treatment ( $3 \mathrm{mg} / \mathrm{kg}$ ) did not cause severe Zn deficiency. Circulating Zn status might be able to maintain homeostasis by mobilizing $\mathrm{Zn}$ from other peripheral tissues like liver during dietary $\mathrm{Zn}$ depletion. Previous studies indeed have shown that $\mathrm{Zn}$ concentrations in liver (14) and bone (15) are decreased in mice when fed the Zn-deficient diet. In this study, LZ group also had lower Zn levels in pancreas and epididymal fat, though non-significant, than that of AZ group (pancreas: $23.2 \pm 9.0$ vs $29.5 \pm 7.5$; fat: $10.7 \pm 2.3 \mathrm{vs} 13.1 \pm 2.4 \mu \mathrm{g} / \mathrm{g}$ tissue).

Chronic inflammation is crucial for the pathogenesis of obesity-related metabolic dysfunctions, including type 2 diabetes mellitus (2). Excess fat mass causes an elevation in circulating proinflammatory markers, like IL-6, TNF $\alpha$, and C-reactive protein (3). PPAR is linked to the negative regulation of macrophage activation through inhibition of NF- $\kappa \mathrm{B}$ and the induced expression of factors like adiponectin (16). On the other hand, subjects with $\mathrm{Zn}$ deficiency are known to catch infections more readily (18). Zn not only participates in humoral immunity by regulating B-cell apoptosis and B-cell response to vaccination, but also affects $T$ helper cells and the cytokines secreted by them, and the activation of natural killer cells (10). Hennig et al. firstly indicated that $\mathrm{Zn}$ can modulate PPARs signaling and associated regulation of inflammation reaction $(8,11)$. Zn deficiency also interacts with rosiglitazone to induce proatherogenic lipid profiles in low-density lipoprotein receptor (LDL-R) KO mice (LDL-R-/-) (14). Although we did not measure circulating cytokines in our mice, the data described above suggest that $\mathrm{Zn}$ nutritional state should modulate the pathogenesis of inflammatory diseases. Interestingly, rosiglitazone has no influence on plasma glucose in LDL-R-/- mice regardless of the amount of zinc intake (14). However, we did find that 2,4-thiazolidinedione effectively reduced hyperglycemia in $\mathrm{db} / \mathrm{db}$ mice, and the efficacy was less in mice with low $\mathrm{Zn}$ intake. The discrepancy in glycemic response might be due to the intrinsic feature of experimental mice (db/db: hyperglycemia or LDL-R-/-: normoglycemia), the dose of $\mathrm{Zn}$ selected to induce $\mathrm{Zn}$ deficiency (3 or $0.4 \mathrm{mg} / \mathrm{kg}$ ), and the type of TZD (2,4-thiazolidinedione or rosiglitazone) administered. Nevertheless, these data indicate that there is an interaction existing between dietary $\mathrm{Zn}$ intake and the activity of PPAR agonists.

In summary, our data confirm that low dietary $\mathrm{Zn}$ intake exacerbates hyperglycemia of the $\mathrm{db} / \mathrm{db}$ mice. Furthermore, low $\mathrm{Zn}$ intake, even at no apparent $\mathrm{Zn}$ deficient status, could attenuate the efficacy of TZD on reducing diabetic hyperglycemia. Therefore, adequate dietary $\mathrm{Zn}$ intake might be critical for diabetic patients when receiving TZD therapy.

\section{Acknowledgement}

We thank Yi-Wen Hong for providing laboratory facilities and technical assistance. We declare no conflict of interest. 


\section{REFERENCES}

1. Andrikopoulos S, Blair AR, Deluca N, Fam BC, Proietto J: Evaluating the glucose tolerance test in mice. Am. J. Physiol. Endocrinol. Metab. 295, E1323-E1332 (2008)

2. Ceriello A: New insights on oxidative stress and diabetic complications may lead to a "causal" antioxidant therapy. Diabetes Care 26, 1589-1596 (2003)

3. Chawla A, Nguyen KD, Goh YP: Macrophage-mediated inflammation in metabolic disease. Nat. Rev. Immunol. 11, 738-749 (2011)

4. Hsu MH, Palmer CN, Song W, Griffin KJ, Johnson EF: A carboxyl-terminal extension of the zinc finger domain contributes to the specificity and polarity of peroxisome proliferator-activated receptor DNA binding. J. Biol. Chem. 273, 27988-27997 (1998)

5. Hung YJ, Lin SH, Pei D, Kuo SW, Hsieh CH, He CT, Hsing LC, Fan SC, Sheu WH: Rosiglitazone improves insulin sensitivity in nonobese subjects with impaired glucose tolerance. Metabolism 55, 439-444 (2006)

6. Jansen J, Karges W, Rink L: Zinc and diabetes: clinical links and molecular mechanisms. J. Nutr. Biochem. 20, 399-417 (2009)

7. Maret W: Zinc biochemistry: from a single zinc enzyme to a key element of life. Adv. Nutr. 4, 82-91 (2013)

8. Meerarani P, Reiterer G, Toborek M, Hennig B: Zinc modulates PPARr signaling and activation of porcine endothelial cells. J. Nutr. 133, 3058-3064 (2003)

9. Myers SA, Nield A, Myers M: Zinc transporters, mechanisms of action and therapeutic utility: implications for type 2 diabetes mellitus. J. Nutr. Metab. 2012, 173712 (2012)

10. Prasad AS: Impact of the discovery of human zinc deficiency on health. J. Am. Coll. Nutr. 28, 257-265 (2009)

11. Reiterer G, Toborek M, Hennig B: Peroxisome proliferator activated receptors a and r require zinc for their antiinflammatory properties in porcine vascular endothelial cells. J. Nutr. 134, 1711-1715 (2004)

12. Semple RK, Chatterjee VK, O’Rahilly S: PPAR gamma and human metabolic disease. J. Clin. Invest. 116, 581-589 (2006)

13. Shaw JE, Sicree RA, Zimmet PZ: Global estimates of the prevalence of diabetes for 2010 and 2030. Diabetes Res. Clin. Pract. 87, 4-14 (2010)

14. Shen H, MacDonald R, Bruemmer D, Stromberg A, Daugherty A, Li X, Toborek M, Hennig B: Zinc deficiency alters lipid metabolism in LDL receptor-deficient mice treated with rosiglitazone. J. Nutr. 137, 2339-2345 (2007)

15. Simon SF, Taylor CG: Dietary zinc supplementation attenuates hyperglycemia in db/db mice. Exp. Biol. Med. 226, 43-51 (2001)

16. Tontonoz P, Spiegelman BM: Fat and beyond: the diverse biology of PPARgamma. Ann. Rev. Biochem. 77, 289-312 (2008)

17. Vardatsikos G, Panday NR, Srivastava AK: Insulino-mimetics and anti-diabetic effects of zinc. J. Inorg. Biochem. 120, 8-17 (2013)

18. Wessells KR, Brown KH: Estimating the global prevalence of zinc deficiency: results based on zinc availability in national food supplies and the prevalence of stunting. PLoS. One. 7, e50568 (2012) 